\title{
Seen from the other side: visual experiences during cataract surgery under topical anaesthesia
}

\author{
Kuang $\mathrm{Hu}$, Stephen Scotcher
}

Patients who have cataract surgery under topical local anaesthetic can have colourful visual experiences. Here two such patients share their paintings inspired by what they saw

Cataract extraction is common, often done under topical local anaesthesia using modern small incision surgery. Patients are fully conscious during the procedure and can have surprisingly colourful visual experiences. ${ }^{1-4}$

\section{Participants, methods, and results}

SS performed uncomplicated small incision phacoemulsification and intraocular lens implantation on two of our patients. The anaesthesia used was proxymetacaine $0.5 \%$ eye drops. The patients subsequently painted their intraoperative visual experiences (figs 1 and 2). These artworks show the colourful images that may be seen during surgery.

One patient is a professional artist and the other is a keen amateur painter. They did not receive preoperative counselling about the possibility of experiencing colourful visual imagery. The authors neither asked the patients to take any particular note of their visual experiences nor solicited the images before surgery. No sedatives were given before or during surgery. The patients worked independently to produce paintings within 48 hours of their operations.

\section{Comment}

These paintings share certain features with the only other published work depicting a patient's visual experience under topical anaesthesia. ${ }^{4}$ The precise origin of the surprisingly vibrant imagery is a matter for speculation. ${ }^{4}$ No coloured agents are used during routine cataract surgery, and the bright operating light that illuminates the eye may partially desensitise its retinal photoreceptors. One author has postulated stimulation of the photoreceptors by ultrasonic energy from the phacoemulsification probe. ${ }^{4}$ Another explanation might be that light from the operating microscope is being refracted into its constituent colours at changing optical interfaces in the eye.

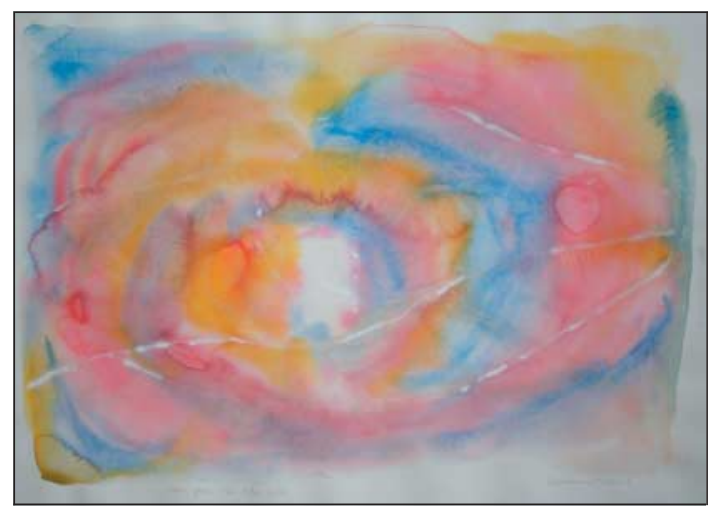

Fig 1 Visual experience of an artist who had cataract surgery

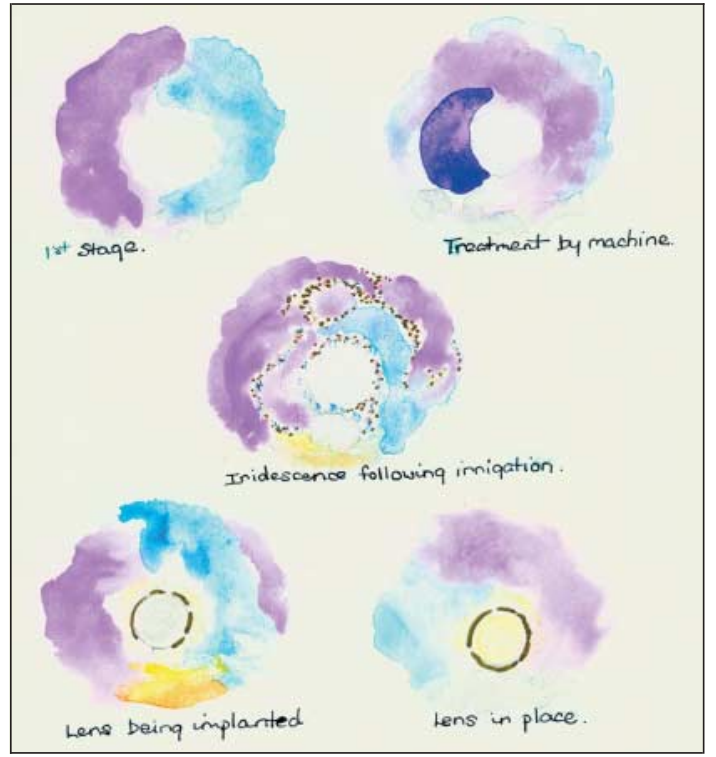

Fig 2 Colourful abstract imagery changed during the procedure

Topical anaesthesia (eye drops alone) does not block optic nerve function. In contrast, other forms of local anaesthesia, such as retrobulbar or peribulbar injections, may block conduction through the optic nerve, potentially reducing visual function and the experience of abstract imagery. ${ }^{35}$ Despite this deeper level of ocular anaesthesia, patients may still experience colourful phenomena during cataract surgery. ${ }^{35}$

A few patients find their intraoperative visual experiences frightening. ${ }^{23}$ Consequently, it may be helpful to counsel patients preoperatively using images of their likely visual experiences. ${ }^{5}$ Such images may thus have clinical importance as well as being of artistic interest.

We thank our patients for allowing us to publish their paintings. Contributors: SS conceived the idea for the paper. KH drafted the manuscript and revised it with SS. SS is guarantor.

Competing interests: None declared.

1 Newman DK. Visual experience during phacoemulsification cataract surgery under topical anaesthesia. Br J Ophthalmol 2000;84:13-5.

2 Au Eong KG, Low CH, Heng WJ, Aung T, Lim TH, Ho SH, Yong VS. SubAu Eong KG, Low CH, Heng WJ, Aung T, Lim TH, Ho SH, Yong VS. Sub-
jective visual experience during phacoemulsification and intraocular lens implantation under topical anesthesia. Ophthalmology 2000;107:248-50.

3 Rengaraj V, Radhakrishnan M, Au Eong KG, Saw SM, Srinivasan A, Mathew J, Ramasamy K, Prajna NV. Visual experience during phacoemulsification under topical versus retrobulbar anesthesia: results of a prospective, randomized, controlled trial. Am J Ophthalmol 2004; 138:782-7.

4 Verma D. Subjective visual experience during phacoemulsification and intraocular lens implantation under topical anesthesia. Ophthalmology $2001 ;$ 108:1004-5.

5 Sumich PM, Francis IC, Kappagoda MB, Alexander SL. Artist's impression of endocapsular phacoemulsification surgery. J Cataract Refract Surg 1998;24:1525-8.
Victoria Eye Unit, Hereford County Hospital, Hereford, HR1 2ER

Kuang $\mathrm{Hu}$ senior house officer in ophthalmology Stephen Scotcher consultant ophthalmic surgeon

Correspondence to: S Scotcher Stephen.Scotcher@ hhtr.nhs.uk

BMJ 2005;331:1511 